Die

Theorie und Praxis

der

Ge b II I t s h ü I f e. 

Die

\section{Theorie und Praxis}

der

\section{Ge e lो II I t s i î I f e.}

I) argestellt

V11

\section{Albert Krause,}

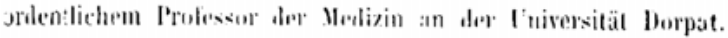

Mit Abbildungen in Stahl und Holz.

Erster Theil.

$$
\text { B e r } 1 \mathrm{in} \text {. }
$$

Druck und Verlag von Georg Reimer.

1853. 
